\title{
Degradation of Co-Evaporated Perovskite Thin Film in Air
}

Congcong Wang, ${ }^{1}$ Youzhen $\mathrm{Li},{ }^{2}$ Xuemei Xu, ${ }^{2}$ Chenggong Wang, ${ }^{1}$ Fangyan Xie, ${ }^{3}$ Yongli $\mathrm{Gao}^{1,2 *}$

${ }^{1}$ Department of Physics and Astronomy, University of Rochester, Rochester, NY, 14627, USA

${ }^{2}$ School of Physics and Electronics, Central South University, Changsha, Hunan, 410083, P. R. China

${ }^{3}$ Instrumental Analysis Center, Sun Yat-Sen University, Guangzhou, 510275, P.R. China

*E-mail: ygao@pas.rochester.edu

\begin{abstract}
Methylammonium lead halide perovskites as highly promising photovoltaic materials have been found unstable in air. We investigated the degradation of $\mathrm{CH}_{3} \mathrm{NH}_{3} \mathrm{PbI}_{3}$ by air exposure using x-ray diffraction (XRD), x-ray photoelectron spectroscopy (XPS), and atomic force microscopy (AFM). The stoichiometric sample was grown with co-evaporation of $\mathrm{PbI}_{2}$ and $\mathrm{CH}_{3} \mathrm{NH}_{3} \mathrm{I}$ on a $\mathrm{Au}$ coated $\mathrm{Si}$ wafer. It was found that the perovskite thin film gradually turned to $\mathrm{PbI}_{2}$ in air, accompanied with complete removal of $\mathrm{N}$ and substantial reduction of $\mathrm{I}$. It was also observed that $\mathrm{PbI}_{2}$ crystallization roughened the film and resulted in a partial exposure of the Au substrate.
\end{abstract}

Key Words: perovskite, co-evaporation, air exposure, degradation 


\section{Introduction}

Recently, organometal trihalide perovskites have emerged as a new generation of photovoltaic materials with high power conversion efficiency (PCE). ${ }^{[1-6]}$ Among various perovskites, methylammonium lead halide perovskites $\left(\mathrm{CH}_{3} \mathrm{NH}_{3} \mathrm{PbX} 3, \mathrm{X}=\mathrm{Cl}\right.$, $\mathrm{Br}$, I) have advantages of wide absorption range, high charge-carrier mobility, and low cost. ${ }^{[7-13]}$ The first solid-state perovskite solar cell with a PCE of $9.7 \%$ was reported in 2012 by H. S. Kim and co-workers ${ }^{[14]}$. Ball et al. found that planar heterojunction perovskite solar cell could get around 5\% efficiency ${ }^{[15]}$. This means that perovskite solar cells can be fabricated with lower cost and higher production efficiency. The PCE was quickly improved to $15.4 \%{ }^{[16]}$, and even $19.3 \%$ in the following years ${ }^{[17]}$. As reported, a small area organic-inorganic halide perovskite cell has reached the efficiency of $20.1 \% .^{[18]}$ Despite the rapid progress in efficiency during past years, perovskite solar cells exhibit significant degradation over a relatively short period of time. ${ }^{[19]}$ Grätzel and co-workers reported that perovskite solar cell could be fabricated under controlled atmospheric conditions with a humidity $<1 \%{ }^{[20]}$. Yang and co-workers reported that perovskite solar cell prepared by $\mathrm{PbCl}_{2}$ and $\mathrm{CH}_{3} \mathrm{NH}_{3} \mathrm{I}$ in controlled moisture environment could get a good crystal structure and the PCE of $17.1 \%{ }^{[21]}$. The reports all mentioned that the performance of perovskite solar cell was sensitive to moisture. More recently, Niu et al. observed the degradation process and proposed that the degradation progressed with $\mathrm{H}_{2} \mathrm{O}$ as a catalyst. ${ }^{[22]}$ Kamat et al. showed that $\mathrm{H}_{2} \mathrm{O}$ is able to react with perovskite in darkness, 
forming a hydrate product similar to $\left(\mathrm{CH}_{3} \mathrm{NH}_{3}\right)_{4} \mathrm{PbI}_{6} \cdot 2 \mathrm{H}_{2} \mathrm{O} \cdot{ }^{[23]}$ Kelly et al. suggested the formation of a hydrated intermediate containing isolated $\mathrm{PbI}_{6}{ }^{4-}$ octahedra as the first step of the degradation process. ${ }^{[24]}$ It remains a critical issue to understand this degradation to better control and develop perovskite solar cells that are suitable for renewable energy applications.

In this article, we present our investigations on the degradation of $\mathrm{CH}_{3} \mathrm{NH}_{3} \mathrm{PbI}_{3}$ by air exposure. The evolution of the film was monitored with x-ray diffraction (XRD) at predetermined time intervals while being exposed to air. It was found that the perovskite thin film gradually turned to $\mathrm{PbI}_{2}$, and it took 22 hours to destroy the perovskite completely within the XRD probing depth. X-ray photoelectron spectroscopy (XPS) was used to characterize the composition before and after the air exposure. Atomic force microscopy (AFM) was used to monitor changes of the surface morphology. The XRD, XPS, and AFM provide a comprehensive picture of $\mathrm{CH}_{3} \mathrm{NH}_{3} \mathrm{PbI}_{3}$ degradation, characterized by the complete removal of $\mathrm{N}$, substantial reduction of $\mathrm{I}$, partial oxidation of $\mathrm{Pb}$, and roughening of the film by $\mathrm{PbI}_{2}$ crystallization.

\section{Experimental}

Fabrication conditions: The co-evaporation process was prepared in a modified Surface Science Laboratories' SSX-100 system. This ultra-high vacuum (UHV) chamber consists of two interconnecting chambers, an evaporation chamber to perform the co-evaporated sample, and an analyzer chamber to do the XPS measurements. The base pressure of the evaporation chamber is typically $1 \times 10^{-7}$ torr. And it is $1 \times 10^{-10}$ torr for the 
analyzer chamber. An X-ray monochromator equipped in the analyzer chamber has a high-throughput bent quartz crystal providing monochromatic Al Ka radiation (1486.6 $\mathrm{eV})$. The energy resolution of the XPS is about $0.6 \mathrm{eV}$. The position of the X-ray spot on the sample can be precisely tuned by the microscope mounted on top of the chamber. And the energy of the photoelectrons was measured by a $40-\mathrm{mm}$ diameter high-resolution detector with parallel detection.

Materials and Sample Preparation: $\mathrm{PbI}_{2}$ powder was purchased from Wuhan Jingge Solar Cells limited Company. $\mathrm{CH}_{3} \mathrm{NH}_{3} \mathrm{I}$ powder was purchased from Shanghai Zhenpin limited Company (99\% purity). The $\mathrm{PbI}_{2}$ and $\mathrm{CH}_{3} \mathrm{NH}_{3} \mathrm{I}$ powders were loaded into two boats in the evaporation chamber, and each boat was attached with a thermal couple tightened near the center of the boat to get the evaporation temperature. The substrate is a Au coated silicon wafer. It was cleaned with methanol in ultrasound before loaded into the evaporation chamber. After mounting the evaporation sources, the $\mathrm{PbI}_{2}$ and $\mathrm{CH}_{3} \mathrm{NH}_{3} \mathrm{I}$ were degassed at the temperature near the evaporation point for about 10 mins. Then, we evaporated $\mathrm{PbI}_{2}$ and $\mathrm{CH}_{3} \mathrm{NH}_{3} \mathrm{I}$ independently to get accurate growth rates, respectively. Because of the limitations of space in our growth chamber, only one quartz crystal microbalance was used to read the deposition rate and the film thickness (mass equivalent thickness) during the co-evaporation process. It is challenging and extensive care must be exercised to fabricate perovskite samples reproducibly. The $\mathrm{PbI}_{2}$ evaporation rate was kept at $\sim 1.1 \AA$ 解 at $\sim 330{ }^{\circ} \mathrm{C}$, while the $\mathrm{CH}_{3} \mathrm{NH}_{3} \mathrm{I}$ evaporation rate was kept at $\sim 1.6$ 
$\AA / m i n$ at $\sim 148{ }^{\circ} \mathrm{C}$. Three different perovskite samples were prepared in the same conditions by co-evaporation with the thickness of $60 \mathrm{~nm}$. Sample 1 was used to show the XRD patterns. It was capped with $2 \mathrm{~nm} \mathrm{PbI}_{2}$ to render some protection over the perovskite layer against the moisture impact in air so as to get more accurate XRD results for the as grown film. Sample 2 was used for XPS measurements. It was transferred into the analyzer chamber to measure the XPS data without breaking the vacuum after the co-evaporation process. Sample 3 was used for AFM measurements. All measurements were performed at room temperature.

Characterizations: The crystalline structure of perovskite film was identified by XRD collected with a Philips APD diffractometer. The XRD diffractometer was equipped with a $\mathrm{Cu} \mathrm{K \alpha} \mathrm{X}$-ray tube operated at $40 \mathrm{kV}$ and $30 \mathrm{~mA}$ using a step size of 0.030 degrees and a time per step of $1.0 \mathrm{~s}$. Our sample was mounted on a low background holder. The measurements started immediately after the film was brought out of UHV chamber. XRD spectra were measured at 76.4 F, 25\% humidity level, and each measurement took about $0.5 \mathrm{~h}$. Experimental fitting of the X-ray data was carried out from $10-70^{\circ} 2 \theta$ at a fixed omega angle of 1 degree. The surface and interface information was measured by XPS with $\mathrm{Al} \mathrm{Ka}$ radiation. Morphology of co-evaporated and air-exposed film was observed by using the NTMDT AFM Microscope.

\section{Results and Discussion}

The $60 \mathrm{~nm} \mathrm{CH}_{3} \mathrm{NH}_{3} \mathrm{PbI}_{3}$ thin film was grown by co-evaporation of $\mathrm{PbI}_{2}$ and $\mathrm{CH}_{3} \mathrm{NH}_{3} \mathrm{I}$ on a Au coated $\mathrm{Si}$ wafer. The composition was verified with XPS to be of 
the atomic ratio $(\mathrm{C}: \mathrm{N}: \mathrm{Pb}: \mathrm{I}: \mathrm{O}=1.29: 1.07: 1.00: 2.94: 0)$, very close to the ideal $\mathrm{CH}_{3} \mathrm{NH}_{3} \mathrm{PbI}_{3}$. The $\mathrm{XRD}$ scan demonstrated it to be crystalline perovskite $\mathrm{CH}_{3} \mathrm{NH}_{3} \mathrm{PbI}_{3}$. For this study, it is critical to use co-evaporated thin film not only because it provides a superior morphology, ${ }^{[16]}$ but also the surface composition close to the ideal ratio is suitable for surface analysis, a condition hardly reached with the spin cast methods widely used in device fabrications. ${ }^{[8,9,12,13,25-28]}$

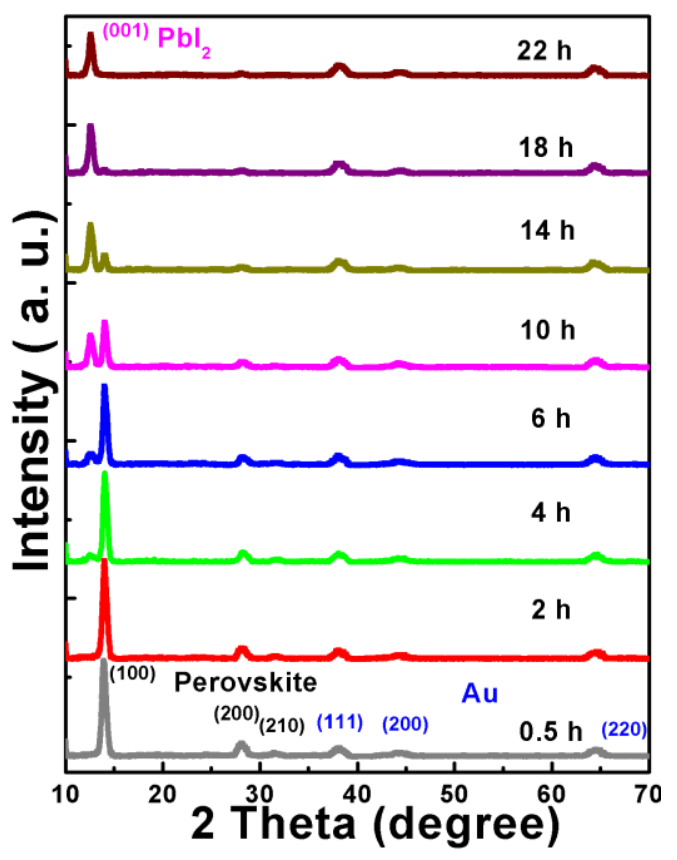

Figure 1. Time evolution of XRD patterns of co-evaporated perovskite film exposed in air.

The perovskite features decrease and the $\mathrm{PbI}_{2}$ one increases as the exposure progresses.

Shown in Figure 1 is the time evolution of XRD patterns of the co-evaporated perovskite film exposed to air (76.4 F, 25\% humidity level). As shown in the bottom pattern, three main perovskite peaks are observed in the pristine sample at $14.02^{\circ}, 28.20^{\circ}$ and $31.52^{\circ}$, assigned to the (100), (200) and (210) lattice planes, respectively. For the region between $14.02^{\circ}$ and $28.20^{\circ}$, there are two very small peaks at $21.22^{\circ}$ and $24.61^{\circ}$ 
from the (110) and (111) diffraction peaks of $\mathrm{CH}_{3} \mathrm{NH}_{3} \mathrm{PbI}_{3}$, respectively. These peaks indicate a cubic crystal structure ${ }^{[7]}$. Other three peaks at $38.19^{\circ}, 44.38^{\circ}$ and $64.58^{\circ}$ are the (111), (200) and (220) diffractions of the Au substrate, respectively. It can be seen clearly that the intensities of the three perovskite peaks gradually reduce as the time of air exposure increases, while the peak at $12.68^{\circ}$, corresponding to the (001) diffraction of $\mathrm{PbI}_{2}$, grows during the process. Notably, the film completely converted from $\mathrm{CH}_{3} \mathrm{NH}_{3} \mathrm{PbI}_{3}$ to $\mathrm{PbI}_{2}$ within the $\mathrm{XRD}$ probing depth at the angle after exposed to air in about 22 hours.

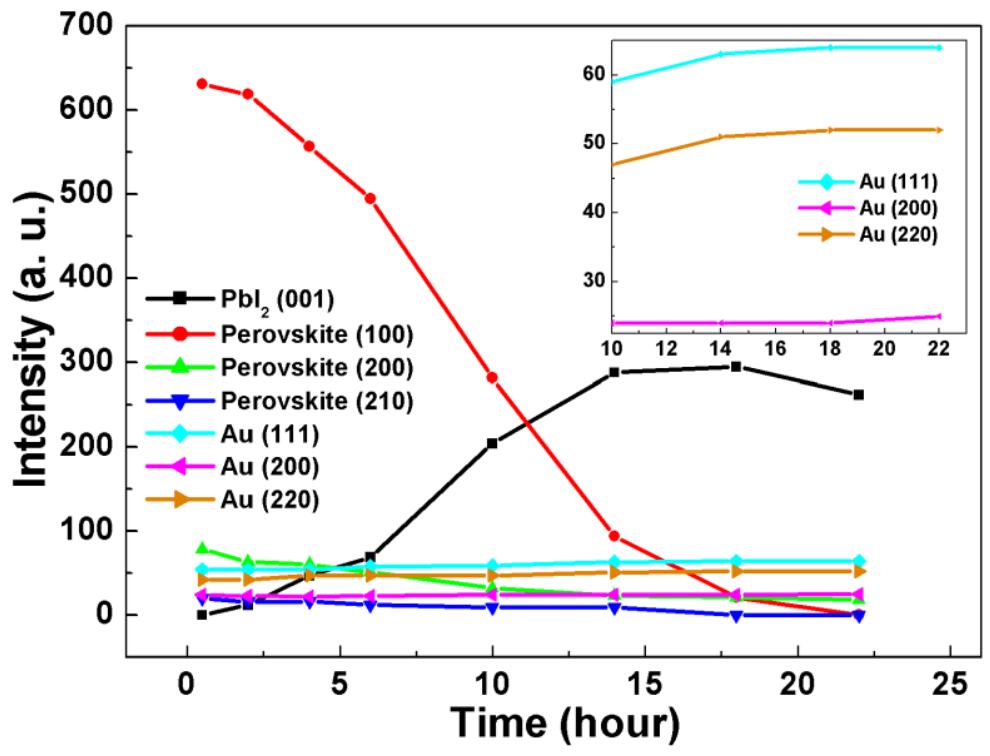

Figure 2. Peak intensity evolution of of $\mathrm{PbI}_{2}, \mathrm{CH}_{3} \mathrm{NH}_{3} \mathrm{PbI}_{3}$ and $\mathrm{Au}$. The decrease of the perovskite and the increase of $\mathrm{PbI}_{2}$ are synchronized. The inset shows the small increase of the substrate $\mathrm{Au}$ signal at higher exposures, attributed to the roughening of the film by $\mathrm{PbI}_{2}$ crystallization.

The XRD peak heights are plotted in Figure 2 as a function of air exposure time. 
The $\mathrm{CH}_{3} \mathrm{NH}_{3} \mathrm{PbI}_{3}$ (100) peak intensity decreases monotonically to zero. The initial slower rate may be due to the limited protection of the $2 \mathrm{~nm} \mathrm{PbI} 2$ layer. The $\mathrm{PbI}_{2}$ peak is increasing with exposure time, reciprocal to that of the $\mathrm{CH}_{3} \mathrm{NH}_{3} \mathrm{PbI}_{3}$ one. The rate of the increase drops down after the exposure time $t_{e x}$ of 10 hours. After 18 hours, there is even a decrease of the $\mathrm{PbI}_{2}$ peak intensity. The Au peaks, have a small increase of the intensity, $\sim 18.52 \%$ and $23.81 \%$, for the (111) and (200) peak, respectively, after 22 hours of exposure. The inset of the figure is the enlarged evolution of the Au peaks after 10 hours of air exposure. The Au intensities increase following the $\mathrm{PbI}_{2}$ decrease when $t_{e x}>18$ hours. There may be two possible explanations. First, it may indicate the decrease of the film thickness. Secondly, it may be due to the crystallization of $\mathrm{PbI}_{2}$. As $\mathrm{PbI}_{2}$ crystals aggregate, voids may initiate in the film and expose the Au substrate.

A more surface sensitive probe like XPS can reveal which of the two possibilities is more likely. Figure 3 is the XPS spectra comparisons of co-evaporated $\mathrm{CH}_{3} \mathrm{NH}_{3} \mathrm{PbI}_{3}$ film before and after air exposure. We have investigated the XPS effect on the film and could not observe any degradation in normal XPS measurement conditions. More extensive XPS investigations on perovskite are presented in Ref. 28. In Fig. 3(a), the full scan of co-evaporated perovskite film shows that there are no obvious other elements except $\mathrm{C}, \mathrm{N}$, $\mathrm{Pb}$ and I, indicating the uniformity and stoichiometry of the perovskite film. For the full scan of air-exposed film, the red marks show the appearance of $\mathrm{Au}$ and $\mathrm{O}$ peaks, while the element name in blue denotes the disappearance of $\mathrm{N} 1 \mathrm{~s}$. This is because of the decomposition of the co-evaporated perovskite into $\mathrm{PbI}_{2}$, as presented in the XRD results, 
and the absorption of moisture in air. The appearance of $\mathrm{Au}$ indicates that the film is roughened by air exposure as the perovskite decomposes and $\mathrm{PbI}_{2}$ crystals aggregate. This is because the mean free path of the XPS is only $\sim 2 \mathrm{~nm}$, unable to penetrate the film and detect the underlying Au. It can be therefore concluded that it is unlikely the decrease of the film thickness but rather the increasing roughness that leads to the XRD and the XPS detections of Au in the air-exposed film. In Figure 3(c), we compared core levels of $\mathrm{C} 1 \mathrm{~s}, \mathrm{~N} \mathrm{1s}, \mathrm{Pb} 4 \mathrm{f}$ and I 3d of co-evaporated and air-exposed film. Black peaks denote the co-evaporated perovskite, while red peaks denote the film after air exposure for $\sim 24$ hours. For the convenience of comparison, we normalized all peaks. There is an obvious shift of C 1s binding energy from $286.2 \mathrm{eV}$ to a higher level of $287.66 \mathrm{eV}$ after the air exposure, which may due to the decomposition of the film into $\mathrm{PbI}_{2}$. Its intensity also decreased about $50 \%$. On the other hand, the peak at $284.55 \mathrm{eV}$ marked by a pink bar is amorphous $\mathrm{C}$ of the air-exposed film. It increased by $110 \%$, indicating the contamination of carbon in air. For N 1s, it disappeared after air exposure, the same result as discussed in XPS full scan. For $\mathrm{Pb} 4 \mathrm{f}$ and I $3 \mathrm{~d}$, there is no shift of core levels. However, the intensities of peaks are different. 


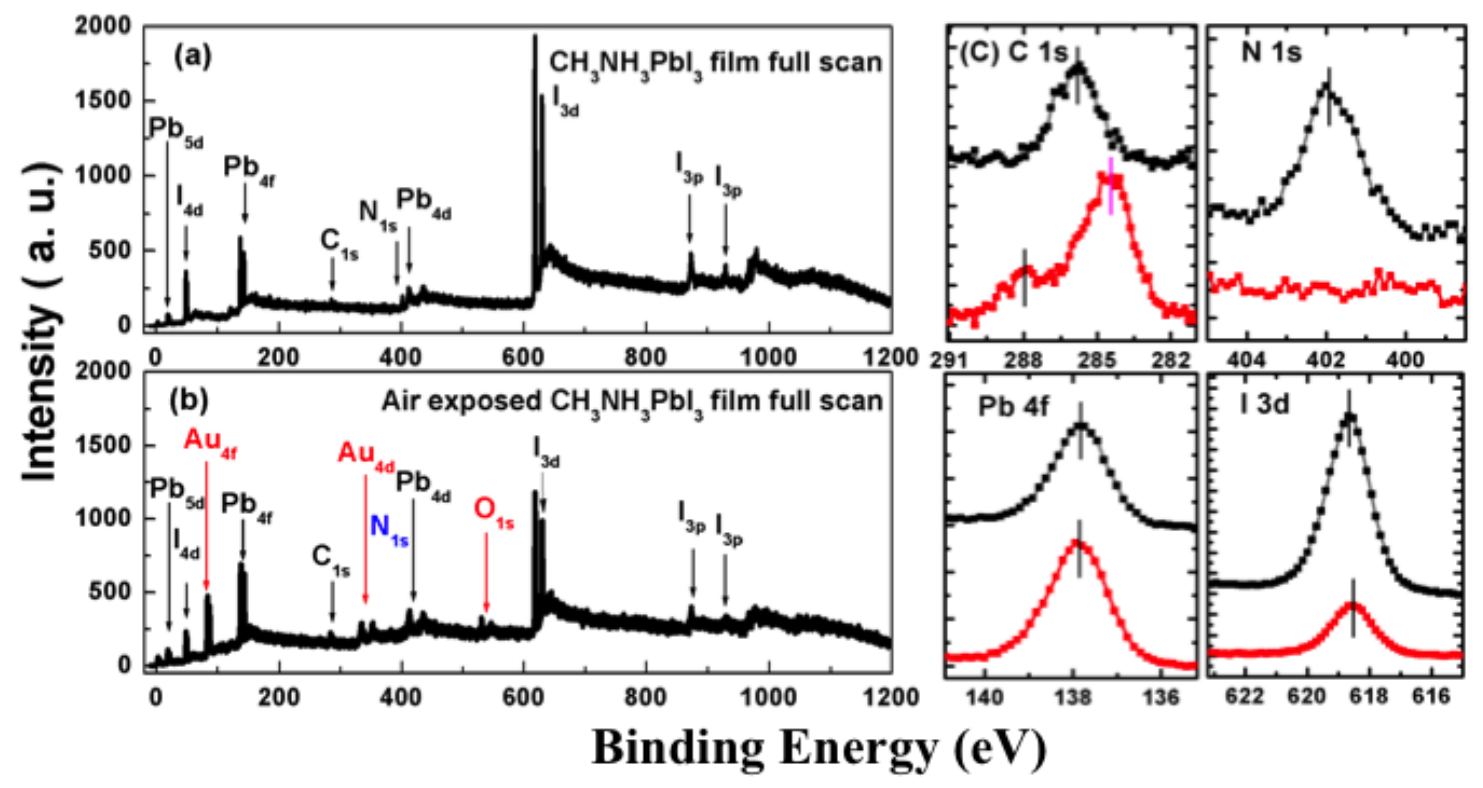

Figure 3. (a) XPS full scan of co-evaporated perovskite film and (b) XPS full scan of air-exposed film. The peaks of different elements are all marked. Red marks denote new elements showed in air-exposed film, and the element name in blue denotes the element vanished in air-exposed film, compared with the co-evaporated perovskite. (c) XPS spectra comparisons of C $1 \mathrm{~s}, \mathrm{~N} 1 \mathrm{~s}, \mathrm{~Pb} 4 \mathrm{f}$, and I 3d core levels, as shown with short bars, of co-evaporated perovskite (black peaks) and air-exposed film (red peaks). Black bars denote the original peaks and the pink bar denotes the new peak. All peaks are normalized for the convenience of comparison.

Table 1. Atomic Ratio of co-evaporated film before and after air exposure.

\begin{tabular}{llllll}
\hline Element & $\mathrm{C}$ & $\mathrm{N}$ & $\mathrm{Pb}$ & $\mathrm{I}$ & $\mathrm{O}$ \\
\hline Ratio & 1.29 & 1.07 & 1.00 & 2.94 & 0 \\
$\begin{array}{l}\text { (co-evaporation) } \\
\text { Ratio }\end{array}$ & 2.22 & 0 & 1.00 & 1.26 & 0.58 \\
\begin{tabular}{l} 
(after exposure) \\
\hline
\end{tabular} & & & & & \\
\hline
\end{tabular}

More critical insights can be obtained from the XPS data on the perovskite decomposition. The atomic ratio comparison from XPS is shown in Table 1. All the XPS 
sensitivity factors and instrumental corrections have been taken into account in obtaining the ratios from the XPS peak areas, and gaussian fitting was used to analyze all peaks. We took the atomic value of $\mathrm{Pb}$ as the basis of the atomic ratio as it is the most stable one among the constituents. For the co-evaporated perovskite, the ratio is $\mathrm{C}: \mathrm{N}: \mathrm{Pb}: \mathrm{I}: \mathrm{O}=$ 1.29: 1.07: 1.00: 2.94: 0 , which is very close to the ideal stoichiometric ratio of $\mathrm{CH}_{3} \mathrm{NH}_{3} \mathrm{PbI}_{3}$ and much superior than those from spin cast ones. ${ }^{[8,9,12,13,25-28]}$ The $\mathrm{C}$ content was a little higher than $\mathrm{N}$ and $\mathrm{Pb}$ in the pristine co-evaporated film, whose origin may be because of the remaining carbon contamination on the Au substrate. After air exposure, the ratio became $\mathrm{C}: \mathrm{N}: \mathrm{Pb}: \mathrm{I}: \mathrm{O}=2.22: 0: 1.00: 1.26: 0.58$. Clearly, $\mathrm{N}$ disappeared completely and $\mathrm{O}$ increased a lot because of the absorption of moisture in the air. The $\mathrm{C}$ increase may be attributed to carbon contamination from the air exposure, as well as the residual amorphous $\mathrm{C}$ after the decomposition of the perovskite and the crystallization of $\mathrm{PbI}_{2}$. Iodine decreased during the process as the film transformed from $\mathrm{CH}_{3} \mathrm{NH}_{3} \mathrm{PbI}_{3}$ to $\mathrm{PbI}_{2}$. However, the ratio 1.26 of $\mathrm{I}$ to $\mathrm{Pb}$ is less than the stoichiometric value of $\mathrm{PbI}_{2}$. This may be due to the further decomposition of $\mathrm{PbI}_{2}$ during the process as indicated from the intensity decrease of $\mathrm{PbI}_{2}$ after 18 hours' exposure shown in Fig. 2. And the oxidation of $\mathrm{I}^{-}$to $\mathrm{I}_{2}$ released the iodine from the surface. Based on XRD and XPS results, we propose the following process of perovskite degradation in air:

$$
\mathrm{CH}_{3} \mathrm{NH}_{3} \mathrm{PbI}_{3} \stackrel{\mathrm{H}_{2} \mathrm{O}}{\longrightarrow}\left(-\mathrm{CH}_{2}-\right)+\mathrm{NH}_{3}(\mathrm{~g})+\mathrm{HI}(\mathrm{g})+\mathrm{PbI}_{2}
$$

This is consistent to the water catalytic model proposed by Niu et al., ${ }^{[22]}$ with the 
notion that the process is irreversible once the gaseous components leave. Furthermore, if oxygen is abundant, the $\mathrm{PbI}_{2}$ may be further oxidized to release iodine, which subsequently sublimes into the ambient and leaves the film iodine deficient and oxygen rich. From the $\mathrm{C}$ 1s peak position, the remaining $\mathrm{C}$ is amorphous, but it cannot be ruled out that some carbon hydrates were formed during the process, absorbing $\mathrm{H}_{2} \mathrm{O}$ along the way.

(a)
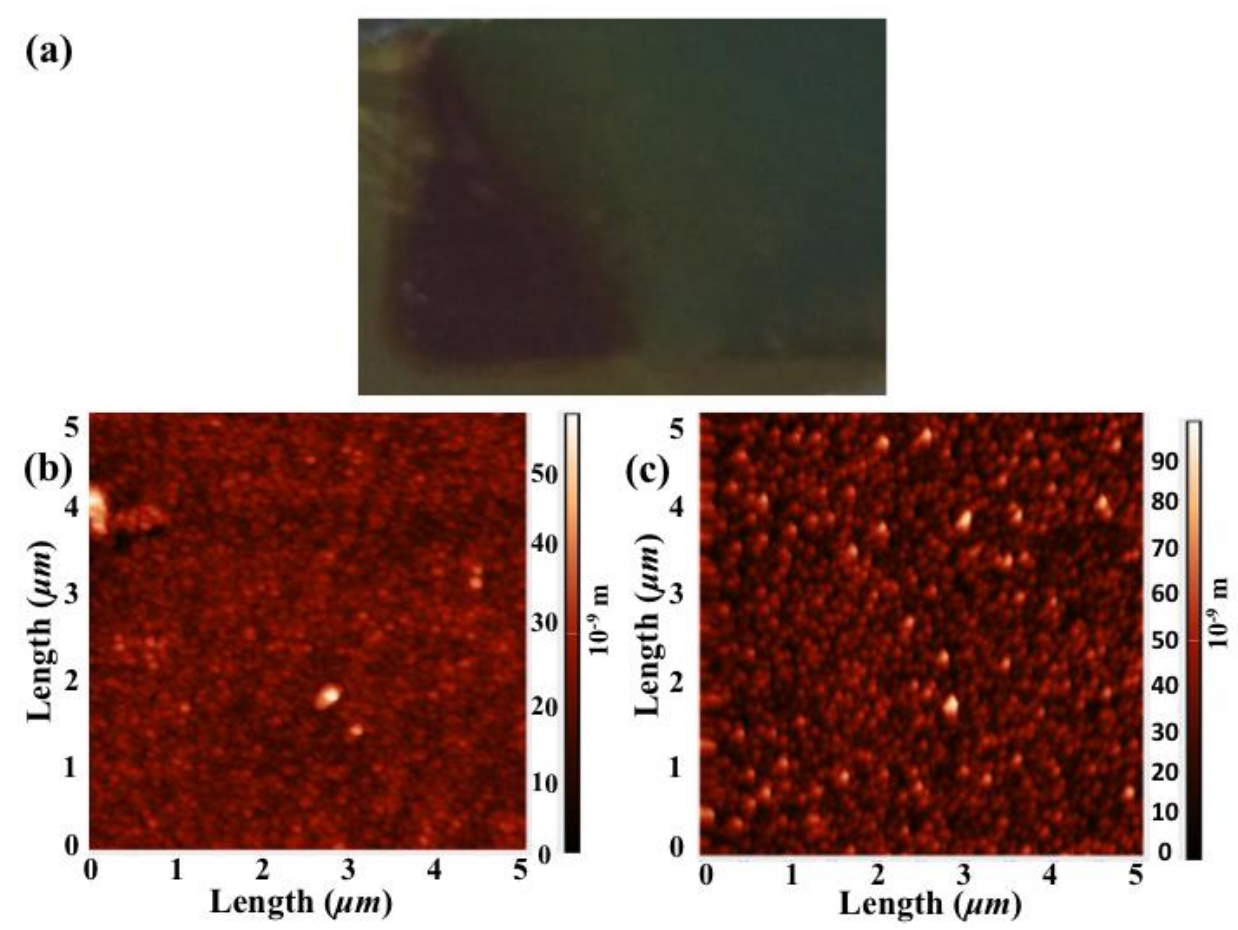

Figure 4. (a) As grown perovskite film (drak brown part) and air-exposed film (green part) on top of $\mathrm{Au} / \mathrm{Si}$ substrate (yellow part). AFM images of co-evaporated perovskite (b) and air-exposed film (c). The size of the images is $5 \times 5 \mu m^{2}$.

In Figure 4, we compared the morphologies of the perovskite film before and after air exposure. When the film was just out of the chamber, it was uniform and the color was dark brown on top of the Au/Si substrate as shown in Fig. 4 (a). After being exposed 
in air for $\sim 24 \mathrm{~h}$, the film became uneven, and the color of it changed to green as shown on the right side in Fig. 4 (a). According to the XRD results, the dark brown film is perovskite, whose AFM image is shown in Fig. 4 (b). The uneven green film is $\mathrm{PbI}_{2}$, whose AFM image is shown in Fig. 4 (c). Clearly, from the AFM image, the air-exposed film is composed of a lot of voids as we expected from the XRD and XPS results, further confirming the crystallization of $\mathrm{PbI}_{2}$ and the exposure of the Au substrate. The film has a more uniform particle height and smaller particle size before air exposure. It is found that the root mean square (RMS) roughness of the film significantly increases from $3.121 \mathrm{~nm}$, indicating the extreme uniformity, to $11.339 \mathrm{~nm}$ after air exposure. The changes of the RMS roughness and particle size confirm our assertion that from $\mathrm{CH}_{3} \mathrm{NH}_{3} \mathrm{PbI}_{3}$ to $\mathrm{PbI}_{2}$, voids are formed with the aggregation of $\mathrm{PbI}_{2}$, causing the partial exposure of the $\mathrm{Au}$ substrate.

\section{Conclusions}

In conclusion, we investigated the air degradation of stoichiometric perovskite thin film grown by co-evaporation of $\mathrm{PbI}_{2}$ and $\mathrm{CH}_{3} \mathrm{NH}_{3} \mathrm{I}$. The XRD measurements revealed that the initial $\mathrm{CH}_{3} \mathrm{NH}_{3} \mathrm{PbI}_{3}$ film transformed to $\mathrm{PbI}_{2}$ after the air exposure. The XPS monitored the composition of the $\mathrm{CH}_{3} \mathrm{NH}_{3} \mathrm{PbI}_{3}$ film before and after the air exposure. The results showed that the moisture in the air catalyzes the decomposition of the perovskite and turns the film into a mixture of amorphous $\mathrm{C}$ and crystalline $\mathrm{PbI}_{2}$, releasing gaseous reaction products during the process. The process is therefore irreversible unless made air-tight. The process also results in film roughening and voids creation, demonstrated by 
the XRD, XPS, and AFM data.

\section{Acknowledgments}

The authors thank the National Science Foundation (Grant Nos. CBET-1437656 and DMR-1303742) for financially supporting this research. Y. L and X. X acknowledge supports from National Natural Science Foundation of China (Grant Nos. 61173047 and 61071025). F. X acknowledges the support from National Natural Science Foundation of China (Grant No. 51303217). Technical supports from the XRD Center in Mechanical Department and the Nanocenter in University of Rochester are highly appreciated. 
1. G. Hodes, Science 342, 317 (2013).

2. H. J. Snaith, J. Phys. Chem. Lett. 4, 3623 (2013).

3. M. M. Lee, J. Teuscher, T. Miyasaka, T. N. Murakami, H. J. Snaith, Science 338, 643 (2012).

4. N. G. Park, J. Phys. Chem. Lett. 4, 2423 (2013).

5. S. Kazim, M. K. Nazeeruddin, M. Grätzel, S. Ahmad, Angew. Chem. Int. Ed. 53, $2812(2014)$.

6. J. H. Heo, S. H. Im, J. H. Noh, T. N. Mandal, C. S. Lim, J. A. Chang, S. I. Seok, Nat. Photonics 7, 486-491 (2013).

7. T. Baikie, Y. N. Fang, J. M. Kadro, M. Schreyer, F. X. Wei, S. G. Mhaisalkar, M. Grätzel, T. J. White, J. Mater. Chem. A 1, 5628-5641 (2013).

8. Z. Xiao, C. Bi, Y. Shao, Q. Dong, Q. Wang, Y. Yuan, C. G. Wang, Y. Gao, J. Huang, Energy Environ. Sci. 7, 2619 (2014).

9. C. G. Wang, X. Liu, C. C. Wang, Z. Xiao, C. Bi, Y. Shao, J. Huang, Y. Gao, J. Vac. Sci. Technol. B 33, 032401 (2015).

10. C. Wehrenfennig, G. E. Eperon, M. B. Johnston, H. J. Snaith and L. M. Herz, Adv. Mater. 26, 1584 (2014).

11. G. Xing, N. Mathews, S. S. Lim, N. Yantara, X. Liu, D. Sabba, M. Grätzel, S. Mhaisalkar, T. C. Sum, Nat. Mater. 13, 476 (2014).

12. C. Bi, Y. Shao, Y. Yuan, Z. Xiao, C. G. Wang, Y. Gao, J. Huang, J. Mater. Chem. A, 2, 18508 (2014).

13. X. Liu, C. G. Wang, L. Lyu, C. C. Wang, Z. Xiao, C. Bi, J. Huang, Y. Gao, Phys. Chem. Chem. Phys. 17, 896 (2015).

14. H. S. Kim, C. R. Lee, J. H. Im, K. B. Lee, T. Moehl, A. Marchioro, S. J. Moon, R. Humphry-Baker, J. H. Yum, J. E. Moser, M. Gratzel and N. G. Park, Sci. Rep. 2, 591 (2012).

15. J. M. Ball, M. M. Lee, A. Hey, H. J. Snaith, Science 6, 1739-1743 (2013). 
16. M. Liu, M. B. Johnston, and H. J. Snaith, Nature 501, 395-398 (2013).

17. H. Zhou, Qi Chen, G. Li, S. Luo, T. B. Song, H. S. Duan, Z. Hong, J. B. You, Y. Liu, and Y. Yang, Science 345, 542-546 (2014).

18. W. S. Yang, J. H. Noh, N. J. Jeon, Y. C. Kim, S. Ryu, J. Seo; S. Il Seok, Science, 6, 1234-1237 (2015).

19. T. Leijtens, G. E. Eperon, S. Pathak, A. Abate, M. M. Lee, H. J. Snaith, Nat. Commun. 4, 2885 (2013).

20. J. Burschka, N. Pellet, S. J. Moon, R. Humphry-Baker, P. Gao, M. K. Nazeeruddin, M. Grätzel, Nature 499, 316-319 (2013).

21. J. B. You, Y.(Michael) Yang, Z. Hong, Tze-Bin Song, L. Meng, Y. S. Liu, C. Y. Jiang, H. P. Zhou, W. H. Chang, G. Li, and Y. Yang, Appl. Phys. Lett. 105, 183902 (2014).

22. G. Niu, W. Li, F. Meng, L. Wang, H. Dong and Y. Qiu, J. Mater .Chem. A 2, 705 (2014).

23. J. A. Christians, P. A. M. Herrera, P. V. Kamat, J. Am. Chem. Soc. 137, 1530-1538 (2015).

24. J. Yang, B. D. Siempelkamp, D. Liu, and T. L. Kelly, ACS Nano 9, 1955-1963 (2015).

25. Q. Wang, Y. Shao, H. Xie, L. Lyu, X. Liu, Y. Gao and J. Huang, Appl. Phys. Lett. 105, 163508 (2014).

26. X. Liu, C. G. Wang, C. C. Wang, I. Irfan and Y. Gao, Org. Elec. 17, 325 (2015).

27. C. G. Wang, C. C. Wang, X. Liu, J. Kauppi, Y. Shao, Z. Xiao, C. Bi, J. Huang and Y. Gao, Appl. Phys. Lett. 106, 111603 (2015).

28. Y Li, X Xu, C. G. Wang, C. C. Wang, F Xie, J Yang, Y Gao, J. Phys. Chem. C. (2015) 